\title{
TENDENCIAS DE REAÇÃO DE FALANTES CURITIBANOS E LONDRINENSES: UM ESTUDO DE CRENÇAS E ATITUDES LINGUÍSTICAS
}

\section{Fabiane Cristina Altino* Dayse de Souza Lourenço Simões* *}

Resumo: Fundamentados na Psicologia Social e na Sociolinguística Variacionista, os estudos de Crenças e Atitudes Linguísticas observam as manifestações da atitude social do indivíduo em relação às variedades linguísticas. Posto isso, este artigo objetiva compreender as atitudes valorativas dos falantes, a percepção sobre sua variedade e a do outro e a presença de estereótipos, em um corpus composto pelas respostas dadas ao instrumento de coleta de dados pelos 24 informantes entrevistados. Este artigo é um estrato da pesquisa de mestrado intitulada Crenças e Atitudes dos falantes de Curitiba e Londrina, defendida em 2015. Esperamos, assim, disseminar os resultados da pesquisa em pauta e colaborar com outros estudos da área.

Palavras-chave: Crenças e atitudes linguísticas. Psicologia Social. Sociolinguística Variacionista.

\section{INTRODUÇÃO}

O ficialmente, o Brasil é um país monolíngue, em que o português é a língua oficial. Entretanto, a realidade linguística brasileira apresenta notável heterogeneidade. Nesse contexto, os falantes reconhecem a existência de diferenças entre os falares e emitem apreciações, podendo demonstrar preferência por uma em detrimento da outra, ou seja, julgando as formas como de maior ou menor prestígio. Todavia, "assim como não existem línguas inferiores, não existem variedades linguísticas inferiores

\footnotetext{
* Universidade Estadual de Londrina (UEL) - Londrina - PR - Brasil.E-mail: fabiane_altino@uol.com.br

** Universidade Anhanguera Uniderp - Campo Grande - MS - Brasil. E-mail: dayse.lourenco1990@gmail.com
} 
[...] os julgamentos sociais ante a lingua - ou melhor, as atitudes sociais - se baseiam em critérios não linguísticos: são julgamentos de natureza política e social" (ALKMIN, 2005, p. 42). Dessa forma, a reação dos falantes em relação às variedades, as avaliações, os julgamentos, as atribuições de estima ou preconceito, entre tantas outras, alicerçam-se no status social em que o falante está inserido.

Posto isso, ressaltamos a estreita relação entre a lingua e a sociedade, pois

Linguagem e sociedade estão ligadas entre si de modo inquestionável. Mais do que isso, podemos afirmar que essa relação é a base da constituição do ser humano. A história da humanidade é a história de seres organizados em sociedades e detentores de um sistema de comunicação oral, ou seja, de uma língua. (ALKMIN, 2005, p. 21).

Assim, observamos a relação íntima entre língua e identidade por meio das atitudes dos indivíduos frente às variedades e, simultaneamente, aos seus usuários, revelando estimas e preconceitos, os quais constituem uma fonte de avaliação, estigmatização, variação e mudança dentro de uma língua (MORENO-FERNÁNDEZ, 1998, p. 257), que figuram no processo de variação e mudança linguística.

Nesse cenário, esta pesquisa, fundamentada nos princípios teórico-metodológicos dos estudos de Crenças e Atitudes Linguísticas, tem como principal objetivo compreender as atitudes valorativas dos falantes, a percepção sobre sua variedade e a do outro e a presença de estereótipos.

\section{Crenças e atitudes linguísticas}

As pesquisas no ramo de Crenças e Atitudes Linguísticas apresentam os dois termos estreitamente imbricados, tornando dificil abordar um sem remeter, automaticamente, ao outro. Este estudo procura, em principio, tratar os dois termos separados, a fim de apresentar uma definição específica para cada um.

Para Daryl Jay Bem, psicólogo social, as crenças estão no eixo cognitivo, porquanto, são "o produto de experiência direta" (BEM, 1973, p. 13). Nesse sentido, as crenças são construídas a partir da inserção do indivíduo em seu contexto social, por meio das experiências e percepções, vinculadas ao estado de espirito e elementos afetivos. Os psicólogos sociais, William e Wallace Lambert (LAMBERT; LAMBERT, 1975), explicam que as crenças são componentes das atitudes, ao lado dos pensamentos, isto é, encontram-se no âmbito cognitivo, ao lado da memória e do raciocínio.

O sociolinguista William Labov (2008) assevera que as crenças são "um conjunto uniforme de atitudes frente à linguagem que são partilhados por quase todos os membros da comunidade de fala, seja no uso de uma forma estigmatizada ou prestigiada da língua em questão" (LABOV, 2008, p. 176), assim, são normalmente compartilhadas dentro de uma comunidade. As crenças são capazes de condicionar o comportamento dos indivíduos, explica Botassini (2013), e é nesse aspecto, em especial, a intersecção com as atitudes linguísticas.

Lambert e Lambert (1975, p. 100), psicólogos sociais, definem atitude como "uma maneira organizada e coerente de pensar, sentir e reagir a pessoas, gru- 
pos, problemas sociais ou, de modo mais geral, a qualquer acontecimento no ambiente". Constituída por pensamentos, crenças, afeição e tendências de reação, portanto, "uma atitude se forma quando tais componentes estão de tal modo inter-relacionados que as tendências de reação e os sentimentos específicos se tornam coerentemente associados ao objeto da atitude" (LAMBERT; LAMBERT, 1975, p.100).

Sintetizando a ideia de vários manuais de Psicologia Social, Rodrigues (1972, p. 397) afirma que atitude é como "uma organização duradoura de crenças e cognições em geral, dotada de carga afetiva pró ou contra um objeto social definido, que predispõe a uma ação coerente com as cognições e afetos relativos a este objeto".

Dotada de conotações sociais, a língua é avaliada consoante ao status social de seus usuários. Assim, as atitudes linguísticas são, normalmente, reguladas pelos grupos sociais de maior prestígio e cumprem papéis importantes exercidos na construção do comportamento dos indivíduos, porquanto "influem em nossos juízos e percepções de outros; influem na rapidez e eficiência de nossa aprendizagem, ajudam a determinar os grupos a que nos ligamos, as profissões que finalmente escolhemos e até a filosofia que aceitamos" (LAMBERT; LAMBERT, 1975, p. 107).

As atitudes podem ser definidas e caracterizadas segundo duas óticas: a mentalista e a comportamentalista (LÓPEZ MORALES, 1993, p. 231). A metalista caracteriza atitude como um estado de disposição mental, uma variável que atua entre um estímulo, afetando a pessoa e sua resposta a esse estímulo. Já a concepção comportamentalista fundamenta-se nas respostas de falantes diante de determinadas situações sociais. Para esse estudo, seguimos a concepção mentalista.

Para os mentalistas, a atitude é "um estado de disposição, uma variável que intervém entre um estímulo que afeta a pessoa e sua reação a ele"1 (LÓPEZ MORALES, 1993, p. 231, tradução nossa) e é constituída por elementos afetivos (emoções e sentimentos), cognitivos (crenças e estereótipos) e comportamentais (tendência à reação de determinado modo).

Figura 1 - Os componentes da atitude

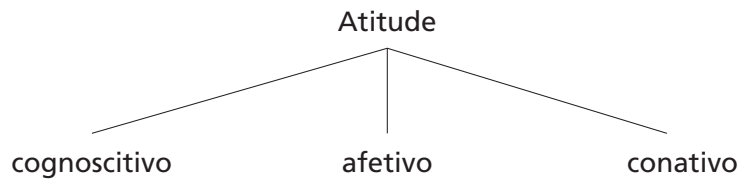

Fonte: Adaptado de López Morales (1993).

O componente afetivo abrange as emoções e sentimentos (LÓPEZ MORALES, 1993, p. 233). Gómez Molina (1998, p. 31) explica que está intimamente vinculado aos valores que a fala representa em uma comunidade, como a identidade, lealdade e o valor simbólico. É indispensável conhecer o objeto social em questão a fim de apresentar uma atitude em relação a ele, afinal, ninguém pode

1 "Un estado de disposición, una variable que interviene entre un estímulo que afecta a la persona y su respuesta a él." 
manifestar um julgamento a respeito do que não conhece, pois, como afirma Rodrigues (1972, p. 398), "para que haja uma carga afetiva pró ou contra um objeto social definido, faz-se mister que haja alguma representação cognitiva do mesmo objeto". Já o componente conativo refere-se à reação ou tendência à reação diante de um objeto social, isto é, "as atitudes possuem um componente ativo, instigador de comportamentos coerentes com as cognições e os afetos relativos aos objetos atitudinais" (RODRIGUES, 1972, p. 400).

Para Lambert (1975), a constituição de uma atitude exige que esses três componentes estejam inter-relacionados de maneira que aquilo que se sente e a forma como se reage diante de um objeto social estejam coerentemente relacionados ao modo como se pensa a respeito dele.

Posto isso, salientamos que as atitudes exercem influência nos fenômenos de variação e mudança linguística, o que instigou os estudiosos a desenvolver técnicas para sua medição e quantificação, apesar da dificuldade embutida nessa tarefa, porquanto as atitudes não são diretamente analisáveis, mas deduzidas. Assim, "as inferências indiretas sobre as atitudes exigem provas cuidadosas para verificação de sua validade - isto é, as medidas de atitudes precisam realmente apreender o que pretendem apreender e não algum outro processo psicológico" (LAMBERT; LAMBERT, 1975, p. 103).

Nesse cenário, os mentalistas preocupam-se em observar o estado interno e mental dos falantes, utilizando técnicas diretas ou indiretas de medição. As medições diretas contam com o auxílio de questionários previamente elaborados, de estrutura aberta, na qual o informante é livre para emitir a resposta que considerar mais adequada, segundo afirma Moreno Fernández (1998). Já as medições indiretas mantêm o objetivo oculto ao informante, como é o caso da técnica matched guises de Lambert (1967), utilizada nesta pesquisa.

A técnica matched guises, ou falsos pares,

envolve as reações de ouvintes (referidos como avaliadores) a gravações de um número de falantes perfeitamente bilingues lendo uma passagem de dois minutos uma vez em uma de suas linguas (ex.: francês) e, em seguida, uma tradução equivalente da mesma passagem em sua segunda lingua (ex.: inglês). Grupos de avaliadores são levados a ouvir essas séries de gravações e a avaliar as características da personalidade de cada falante bem como possível, usando pistas da voz apenas. ${ }^{2}$ (LAMBERT, 1967, p. 93, tradução nossa).

Para a elaboração da pesquisa, primeiramente, foram realizadas gravações de cinco falantes bilíngues lendo o mesmo trecho de um texto duas vezes - em inglês e francês. As gravações foram apresentadas a um grupo de avaliadores que observaram as características pessoais de cada falante segundo as informações vocais e de leitura. Os avaliadores não tinham conhecimento de que se tratava, na verdade, das mesmas pessoas lendo o mesmo texto duas vezes. Para a avaliação, foram observados pontos como competência que engloba inteligên-

\footnotetext{
2 "involves the reactions of listeners (referred to as judges) to the taped recordings of a number of perfectly bilingual speakers reading a two-minute passage a tone time in one of their languages (e.g., French) and, later a translation equivalent of the same passage in their second language (e.g., English). Groups of judges are asked to listen to this series of recordings and evaluate the personality characteristics of each speaker as well as possible, using voice cues only." (LAMBERT, 1967, p. 93).
} 
cia, autoconfiança, ambição; integridade pessoal: sinceridade, caráter, confiabilidade; atratividade social: sociabilidade, empatia.

O precursor da Sociolinguística Variacionista, Labov (2008), afirma que a técnica matched guise é um instrumento básico largamente utilizado em estudos de reações subjetivas à linguagem. A técnica encaminhou um progresso importante na avaliação das reações sociais frente à linguagem com uma metodologia garantida, capaz de capturar as reações dos falantes frente ao objeto em questão.

\section{Procedimentos metodológicos}

Consoante à perspectiva mentalista, optamos pela medição indireta, isto é, o informante não tem consciência do objetivo da investigação. Entre as técnicas de medição indireta, a mais conhecida é a matched guise (falsos pares), de Lambert, a qual utilizamos neste estudo.

Para obter uma amostra dos modos de fala em Curitiba e Londrina, realizamos a gravação da leitura feita por dois narradores com as mesmas características sociais: 50 anos e ensino médio concluído, para que as diferenças diastráticas, diassexuais e diassociais não interferissem no produto da leitura.

O texto selecionado, além de conter as marcas fonéticas diferenciadoras dos dois dialetos, apresenta um tema de cunho científico, expositivo e descritivo para que as atribuições de crenças e atitudes sejam, essencialmente, segundo a voz/fala e não ao conteúdo.

\section{Foco na firmeza}

O novíssimo creme politensor de soja contém um ativo com a proteína do grão que, segundo o fabricante, proporciona um efeito tensor imediato, mas, até aí, a promessa é idêntica à dos outros produtos do mercado. O grande fator diferencial seria o exclusivo dermo glicídio. Trata-se do açúcar vegetal que age nas fibras da pele para retardar a produção do colágeno, substância responsável pela firmeza dos tecidos. Além disso, o lançamento leva um composto que estimula a renovação celular. Está disponivel em versões para diversas faixas etárias, na fórmula diurna e noturna e pode ser encontrado nas farmácias, mercearias e mercados. (BOTASSI, 2009, p. X)

As entrevistas foram gravadas utilizando dois smartphones. Em seguida, apresentamos essas gravações aos avaliadores que, para ouvir com perfeita nitidez, utilizavam fones de ouvido. Aos informantes de Curitiba, foi apresentado primeiro o subdialeto curitibano e depois o londrinense; em Londrina, na ordem inversa. São 12 avaliadores curitibanos e 12 londrinenses, estratificados conforme ilustra a Tabela 1.

É necessário salientar que, para este artigo e por critérios de exiguidade de espaço, as análises referentes à estratificação de sexo, faixa etária e escolaridade não foram explicitadas. ${ }^{3}$

\footnotetext{
3 Para acesso completo às análises, consultar Lourenço (2015).
} 
Tabela 1 - Perfil dos avaliadores

\begin{tabular}{|l|l|l|l|}
\hline Informante & Idade & Escolaridade & Sexo \\
\hline 1 & 18 a 30 & Fundamental & Masculino \\
\hline 2 & 18 a 30 & Fundamental & Feminino \\
\hline 3 & 18 a 30 & Médio & Masculino \\
\hline 4 & 18 a 30 & Médio & Feminino \\
\hline 5 & 18 a 30 & Superior & Masculino \\
\hline 6 & 18 a 30 & Superior & Feminino \\
\hline 7 & 51 a 70 & Fundamental & Masculino \\
\hline 8 & 51 a 70 & Fundamental & Feminino \\
\hline 9 & 51 a 70 & Médio & Masculino \\
\hline 10 & 51 a 70 & Médio & Feminino \\
\hline 11 & 51 a 70 & Superior & Masculino \\
\hline 12 & 51 a 70 & Superior & Feminino \\
\hline
\end{tabular}

Fonte: Elaborado pelas autoras.

Explicamos aos avaliadores que o teste corresponderia ao atendimento telefônico de um estranho e, automaticamente, atribuímos juízos de valor, imaginando como seria o dono da voz. Imediatamente após ouvirem cada gravação, solicitamos que os avaliadores respondessem a uma ficha avaliativa tendo como base a gravação ouvida e, como eram duas gravações, o processo foi realizado duas vezes.

$\mathrm{O}$ instrumento de avaliação refere-se às reações subjetivas dos falantes. A ficha avaliativa utilizada se baseia no trabalho de Bergamaschi (2006) e nas adaptações realizadas a partir dela por Botassini (2013). As questões são:

1. A pessoa que você ouviu é inteligente?

2. A pessoa que você ouviu é feia?

3. A pessoa que você ouviu é estudada?

4. A pessoa que você ouviu é cuidadosa?

5. A pessoa que você ouviu é grossa?

6. A pessoa que você ouviu é trabalhadora?

7. A pessoa que você ouviu é confiável?

8. A pessoa que você ouviu é responsável?

9. A pessoa que você ouviu é preguiçosa?

10. A pessoa que você ouviu é insegura?

11. A pessoa que você ouviu é antipática? 
12. A pessoa que você ouviu é competente?

13. A pessoa que você ouviu é tímida?

14. A pessoa que você ouviu é respeitosa?

15. A pessoa que você ouviu é exibida?

16. A pessoa que você ouviu é autoritária?

17. A pessoa que você ouviu é engraçada?

18. A pessoa que você ouviu é criativa?

19. A pessoa que você ouviu ajuda se alguém precisa?

20. A pessoa que você ouviu sofre preconceito social?

21. A pessoa que você ouviu tem boa cultura?

22. A pessoa que você ouviu tem boa condição financeira?

23. A pessoa que você ouviu tem posto de chefia?

24. A pessoa que você ouviu gosta de falar assim?

Com as entrevistas prontas, transcrevemos a fala dos informantes segundo as técnicas fonética e grafemática do Atlas Linguístico do Brasil (ALiB). Os dados foram tratados por meio do software desenvolvido por Mendez Batista (2012), ${ }^{4}$ que fornece noções estatísticas simples, como número de ocorrências, porcentagens e cruzamento de variáveis.

\section{ANÁlise dos DADOS}

A análise dos dados obtidos parte da adaptação da técnica matched guise, a qual utiliza dois narradores naturais das localidades dos dialetos observados (Curitiba e Londrina), a fim de obter uma amostra dos modos de fala das duas cidades. Contamos com os resultados estatísticos obtidos por meio do programa desenvolvido por Mendez Batista (2012) para as respostas dos informantes ao questionário utilizado por Botassini (2013), por sua vez, adaptado do trabalho de Bergamaschi (2006).

Cada um dos 24 informantes respondeu ao questionário duas vezes, uma vez relacionada ao próprio dialeto e outra relacionada ao dialeto do outro. Assim, o corpus é constituído por 48 fichas avaliativas de 24 perguntas, totalizando 1.152 avaliações. Desse total, $715(62,1 \%)$ respostas são positivas, 318 (27,6\%), negativas. Além dessas avaliações, 119 (10,3\%) dos avaliadores não souberam informar ou preferiram não responder aos questionamentos.

O Gráfico 1 apresenta a apreciação geral das avaliações positivas, negativas e as não respostas.

As avaliações positivas englobam as respostas sim às questões com características positivas e não às questões com características negativas. Já as avaliações negativas são consideradas as respostas sim às questões com características negativas e não às questões com características positivas. Como não resposta estão incluídos os casos em que o avaliador disse não saber responder,

4 Analista de sistemas da Universidade Estadual de Maringá (UEM). 
preferiu não dar resposta ou a resposta foi considerada sem pertinência aos propósitos do trabalho.

Gráfico 1 - Apreciação geral das avaliações positivas, negativas e não respostas

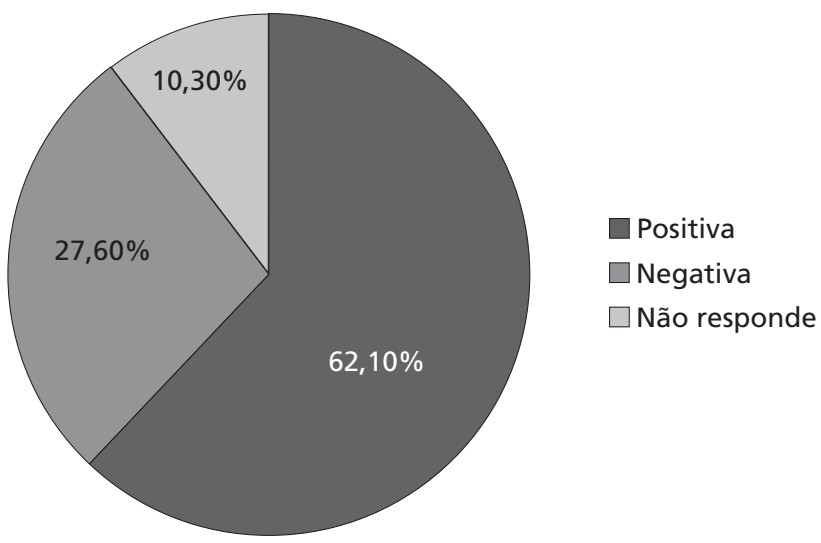

Fonte: Elaborado pelas autoras.

$\mathrm{Na}$ análise geral dos dados, sem observar a procedência dos avaliadores e/ou dialeto avaliado, observamos a maior recorrência de avaliações positivas $(62,10 \%)$, percentual maior que as avaliações negativas $(27,60 \%)$ e as não respostas $(10,30 \%)$ somadas. Esse cenário confirma que os informantes têm maior propensão à atribuição de prestígio linguístico às falas que à atribuição de desprestígio.

A Tabela 2 ilustra a avaliação geral dos dialetos ouvidos sem levar em conta a procedência dos julgadores.

Tabela 2 - Avaliação geral dos dialetos ouvidos

\begin{tabular}{|l|c|c|c|c|c|c|}
\hline \multirow{2}{*}{ Dialeto ouvido } & \multicolumn{2}{|c|}{ Positiva } & \multicolumn{2}{c|}{ Negativa } & \multicolumn{2}{c|}{ Não resposta } \\
\cline { 2 - 7 } & Quantidade & $\%$ & Quantidade & $\%$ & Quantidade & $\%$ \\
\hline Curitibano & 371 & 64,4 & 152 & 26,6 & 53 & 9,2 \\
\hline Londrinense & 344 & 59,7 & 166 & 28,8 & 66 & 11,5 \\
\hline
\end{tabular}

Fonte: Elaborado pelas autoras.

Os dados atestam o percentual de uma avaliação mais positiva em relação ao falar curitibano $(64,4 \%)$ em comparação ao londrinense $(59,7 \%)$. Enquanto na avaliação negativa, o falar londrinense apresenta um percentual ligeiramente mais elevado $(28,8 \%)$ que o curitibano $(26,6 \%)$. Apesar de a diferença percentual ser pequena, observamos a preferência pelo dialeto curitibano em comparação ao londrinense.

Corroborando com esses dados, Pastorelli (2009), em estudo de crenças e atitudes sobre os falantes de Londrina, observa uma tendência ao desprestígio 
frente ao próprio falar, visto que $57,14 \%$ das respostas indicam que o londrinense considera sua fala errada (PASTORELLI, 2009, p. 50). Em sua tese, Botassini (2013, p. 172) observa um cenário semelhante, pois os resultados de seu estudo apontam que há "certa 'rejeição' [...] à fala norte-paranaense ou, pelo menos, menor estima em relação a ela” (BOTASSINI, 2013, p.172). Em estudo comparativo de crenças e atitudes de falantes de Londrina e Pitanga, as autoras Aguilera e Silva (2014) registram uma postura divergente frente ao falar londrinense, visto que os dados demonstram um quadro de prestígio direcionado a essa variedade e "desvalorização e [...] preconceito em relação ao subdialeto de Pitanga" (AGUILERA; SILVA, 2014, p. 714). Esse fato é decorrente da noção de prestígio linguístico que é, segundo Condé (1998, p.1), intimamente vinculada ao status social.

E quem julga mais positivamente? E mais negativamente? A Tabela 3 ilustra a avaliação geral dos julgadores de Curitiba e Londrina, sem considerar o dialeto julgado, somente o posicionamento dos julgadores.

Tabela 3 - Avaliação geral dos julgadores de Curitiba e Londrina

\begin{tabular}{|l|c|c|c|c|c|c|}
\hline \multirow{2}{*}{$\begin{array}{l}\text { Procedência do } \\
\text { julgador }\end{array}$} & \multicolumn{2}{|c|}{ Positiva } & \multicolumn{2}{c|}{ Negativa } & \multicolumn{2}{c|}{ Não resposta } \\
\cline { 2 - 7 } & Quantidade & $\%$ & Quantidade & $\%$ & Quantidade & $\%$ \\
\hline Curitiba & 327 & 56,8 & 165 & 28,6 & 84 & 14,6 \\
\hline Londrina & 388 & 67,4 & 153 & 26,6 & 35 & 6,1 \\
\hline
\end{tabular}

Fonte: Elaborado pelas autoras.

Os dados atestam a maior ocorrência de atribuição positiva por parte dos avaliadores de Londrina do que os curitibanos. Já as atribuições negativas apresentaram uma diferença pouco significativa. Esses números demonstram que o londrinense tende a reagir mais positivamente frente às variedades, tanto ao próprio dialeto quanto ao dialeto do outro, e parecem indicar que os londrinenses são menos preconceituosos que os curitibanos ou, pelo menos, aceitam melhor as variedades. Os casos de não resposta também são significativos, visto que apenas $6,1 \%$ dos londrinenses não responderam, enquanto $14,6 \%$ dos curitibanos se abstiveram, sugerindo certa cautela ao fazer juízos de valor.

Observar as avaliações segundo a procedência dos avaliadores é fundamental, pois, a partir desses dados, mensuramos as reações frente ao próprio dialeto e em relação ao outro, constatando, assim, as relações de prestígio e desprestígio. A Tabela 4 apresenta os dados em porcentagem e número de ocorrências.

Ao observar os dados apresentados na Tabela 4, verificamos que a reação dos julgadores curitibanos frente aos dois falares apresenta percentuais muito próximos, pois foram atribuídos $57,3 \%$ de atitude positiva, ou prestígio, à fala curitibana, enquanto à fala londrinense, 56,3\%. Os julgamentos realizados pelos londrinenses apresentam percentuais menos próximos, pois foram atribuídos $71,5 \%$ de prestígio, ou atitude positiva, em relação ao falar curitibano e $63,2 \%$ ao falar londrinense. 
Tabela 4 - Avaliação dos dialetos ouvidos segundo a procedência dos julgadores

\begin{tabular}{|l|l|c|c|c|c|c|c|}
\hline \multicolumn{2}{|l}{ Procedência/ Dialetos ouvidos } & \multicolumn{2}{c|}{ Positiva } & \multicolumn{2}{c|}{ Negativa } & \multicolumn{2}{c|}{ Não resposta } \\
\cline { 3 - 9 } & Quant. & $\%$ & Quant. & $\%$ & Quant. & $\%$ \\
\hline \multirow{3}{*}{ Curitiba } & Curitiba & 165 & 57,3 & 80 & 27,8 & 43 & 14,9 \\
\hline \multirow{3}{*}{ Londrina } & Londrina & 162 & 56,3 & 85 & 29,5 & 41 & 14,2 \\
\cline { 2 - 9 } & Curitiba & 206 & 71,5 & 72 & 25,0 & 10 & 3,5 \\
\cline { 2 - 9 } & Londrina & 182 & 63,2 & 81 & 28,1 & 25 & 8,7 \\
\hline
\end{tabular}

Fonte: Elaborado pelas autoras.

Esse cenário permite inferir que o falante curitibano reage de maneira semelhante diante dos dois modos de fala, levando a acreditar que o preconceito, por parte do avaliador curitibano, parece estar minimizado. Esse fenômeno pode ter sido motivado por diversos fatores, entre eles, a maior mobilidade devido aos meios de transporte, a facilidade de convivência e comunicação, e o intercâmbio de cultura por meio de diferentes mídias sociais. Já o falante londrinense atribui maior prestígio ao falar da capital em comparação ao próprio falar. Destacamos a noção de prestígio linguístico, vinculada ao prestígio social, como afirma Condé (1998, p.1), explicando o prestígio atribuído ao falar da capital em detrimento à representante do interior, especialmente do dialeto norte-paranaense que carrega o estereótipo de "caipira". Assim, ao sustentarem essas crenças com o próprio dialeto, os londrinenses indicaram uma atitude negativa frente ao próprio falar que, segundo Calvet (2002, p. 72), ocorre "quando os falantes consideram seu modo de falar pouco valorizador e têm em mente outro modelo, mais prestigioso".

\section{CONSIDERAÇÕES FINAIS}

Os estudos no campo da Sociolinguística e das Crenças e Atitudes Linguísticas buscam compreender as tendências de reação, bem como o comportamento dos indivíduos em relação à sua variedade de fala e à dos outros. Com esse aporte teórico, esta pesquisa buscou compreender as atitudes valorativas dos falantes, a percepção sobre sua variedade e a do outro e a presença de estereótipos.

Assim, a pesquisa examinou as reações dos avaliadores em relação aos dois dialetos ouvidos. Do total de avaliações, $715(62,1 \%)$ respostas foram positivas e $318(27,6 \%)$ negativas. Além dessas avaliações, houve 119 casos $(10,3 \%)$ de abstenção de respostas, porque os avaliadores não souberam ou preferiram não responder. As avaliações positivas foram mais frequentes que as avaliações negativas e as não respostas juntas, indicando que os informantes avaliados tendem a reagir mais positivamente aos dialetos.

Considerando a mínima diferença, sem observar a procedência dos avaliadores, o falar curitibano recebeu mais avaliações positivas $(64,4 \%)$ que o falar londrinense (59,7\%). Na avaliação negativa, o falar londrinense apresenta um percentual ligeiramente mais elevado $(28,8 \%)$ que o curitibano $(26,6 \%)$. Apesar de o percentual das avaliações dos dialetos apresentar uma diferença pequena, a preferência pelo dialeto curitibano em comparação ao londrinense é perceptivel. 
Os avaliadores de Londrina efetuaram mais avaliações positivas $(67,4 \%)$, enquanto os curitibanos julgaram positivamente em $56,8 \%$ dos casos. Apesar de pequena diferença, as avaliações negativas foram mais realizadas pelos julgadores curitibanos, com $28,6 \%$ dos casos, contra $26,6 \%$ dos londrinenses. Os dados demonstram que o londrinense tende a reagir mais positivamente frente às variedades, são menos preconceituosos que os curitibanos ou, pelo menos, aceitam melhor as variedades. As não respostas merecem destaque, pois indicam que o falante londrinense se posiciona mais criticamente ao avaliar que o curitibano. Apenas 6,1\% dos londrinenses não responderam, contra $14,6 \%$ dos curitibanos, sugerindo cuidado ao emitir apreciações.

Ao considerar a procedência dos avaliadores, verificou-se que a reação dos julgadores curitibanos frente aos dois falares apresenta percentuais muito próximos. Foram atribuídos $57,3 \%$ de atitude positiva, ou prestígio, à fala curitibana, enquanto à fala londrinense, 56,3\%. Já os julgamentos realizados pelos londrinenses apresentam percentuais mais significativos, pois foram atribuidos $71,5 \%$ de prestígio, ou atitude positiva, em direção ao falar curitibano e $63,2 \%$ ao falar londrinense.

Os dados demonstram que o falante curitibano reage de maneira semelhante frente aos dois falares, levando a acreditar na não existência de um preconceito por parte do julgador curitibano em relação ao falar londrinense. Ao sustentar uma atitude mais positiva frente ao falar do outro e menos positiva frente ao próprio falar, o falante londrinense demonstra considerar a variedade do outro um modelo de maior prestígio.

Dessa forma, esse artigo espera colaborar com os estudos de Crenças e Atitudes Linguísticas.

\title{
REACTION TRENDS OF SPEAKERS FROM CURITIBA AND LONDRINA: A BELIEFS AND ATTITUDES LANGUAGE STUDY
}

\begin{abstract}
Based on social psychology and variationist sociolinguistics, studies of beliefs and Linguistic Attitudes observe the manifestations of the social attitude of the individual in relation to linguistic varieties. That said, this article aims to understand the evaluative attitudes of speakers, the perception of its variety and the other and the presence of stereotypes in a body composed of the answers given to the data collection instrument by the 24 interviewed informants. This paper is part of the Master thesis titled Beliefs and Attitudes of speakers from Curitiba and Londrina, held in 2015. We hope to disseminate the results of research on the agenda and collaborate with other studies of the area.
\end{abstract}

Keywords: Beliefs and linguistic attitudes. Social psychology. Sociolinguistics variationist. 


\section{REFERÊNCIAS}

AGUILERA, V. A.; SILVA, H. C. O poder de uma diferença: um estudo sobre crenças e atitudes linguísticas. In: ALFA. São Paulo, 2014. Disponivel em: <http:// www.scielo.br/scielo.php?pid=S1981-57942014000300703\&script=sci_arttext $>$. Acesso em: 29 mar. 2016.

ALKMIN, T. M. Sociolingüística. In: MUSSALIM, F.; BENTES, A. C. Introdução à lingüística: domínios e fronteiras. 5. ed. São Paulo: Cortez, 2005.

BEM, D. J. Convicções, atitudes e assuntos humanos. Tradução Carolina Martuscelli Bori. São Paulo: Editora Pedagógica e Universitária, 1973.

BERGAMASCHI, M. C. Z. Bilinguismo de dialeto italiano-português: Atitudes linguísticas. Dissertação (Mestrado em Letras)-Universidade de Caxias do Sul, Caxias do Sul, 2006.

BOTASSINI, J. O. M. Crenças e atitudes linguísticas: um estudo dos róticos em coda silábica no norte do Paraná. Tese (Doutorado em Estudos da Linguagem)Universidade Estadual de Londrina, Londrina, 2013.

CALVET, Jean-Louis. Sociolingüística: uma introdução crítica. Tradução Marcos Marcionillo. São Paulo: Parábola, 2002.

CONDÉ, V. G. O conflito lingüístico na Galiza. In: Anais do II Congresso Nacional de Lingüistica e Filologia. Rio de Janeiro, 1998.

GÓMEZ MOLINA, J. R. Actitudes lingüisticas en uma comunidad bilíngue y multidialectal: área metropolitana de Valencia. Anejo n. 3 XXVIII dela Revista Cuadernos de Filología. Valencia: Universitat de Valencia, 1998.

LABOV, W. Padrões sociolinguísticos. São Paulo: Parábola, 2008.

LAMBERT, W. E. A Social Psychology of Bilingualism. In: Journal of social issues. Vol. XXIII. n.2, 1967.

LAMBERT, W. W.; LAMBERT, W. E. Psicologia social. Tradução Dante Moreira Leite. 4. ed. Rio de Janeiro: Zahar, 1975.

LÓPEZ MORALES, H. Sociolingüistica. Madri: Gredos, 1993.

LOURENÇO, D. Crenças e Atitudes dos falantes de Londrina e Curitiba. 2015. Dissertação (Programa de Pós-Graduação em Estudos da Linguagem)-Universidade Estadual de Londrina, Londrina, 2015.

MORENO FERNÁNDEZ, F. Princípios de Sociolingüistica y Sociologia del Lenguaje. Barcelona: Ariel, 1998.

PASTORELLI, D. S. Atitude linguística de falantes da cidade de Londrina-PR: positiva ou negativa? Monografia. Universidade Estadual de Londrina, Londrina, 2009.

RODRIGUES, A. Psicologia social. Rio de Janeiro: Editora Vozes, 1972.

Recebido em 12-07-2016.

Aprovado em 14-07-2016. 